CDD. 801

\title{
Palimpsestos e sobrevivências: o ser e o sentido na filosofia e na literatura
}

Kelvin Falcão Klein

\begin{abstract}
Resumo: Este artigo analisa posicionamentos teóricos sobre a emergência do ser nos discursos da filosofia e da literatura, focando especialmente as considerações de Jacques Derrida e Gilles Deleuze dentro desse campo. Outros autores, como Giorgio Agamben e Jacques Rancière, constituem apoio para o esboço de uma perspectiva transdisciplinar que visa ao aprimoramento da junção teórica entre filosofia e literatura. $\mathrm{O}$ argumento principal deste texto é o caráter combativo inerente aos discursos aqui considerados, principalmente no que concerne ao percurso delineado quando um campo invade o outro. Esse percurso é observado, aqui, na análise da metaforização presente na construção dos conceitos e na problematização dos resíduos que esse exercício de intelecção acarreta. O espaço da metáfora anuncia o palimpsesto e a teoria dos resíduos é codificada nas sobrevivências.

Palavras-chave: Desconstrução; Interdisciplinaridade; Metáfora.

Abstract. This article examines theoretical positions on the emergence of the human being in philosophy and literature discourses, focusing especially on the considerations of Jacques Derrida and Gilles Deleuze. Other authors such as Giorgio Agamben and Jacques Rancière support the outline of a transdisciplinary approach that aims to improve the theoretical link between philosophy and literature. The main argument of this text is the combative character inherent to the discourses analyzed, in particular when one field invades the other. This path is observed in the analysis of metaphorization in the construction of concepts that involve the exercise of intellection. The space of metaphor announces the palimpsest and the theory of residues is encoded in the survivors.

Keywords. Deconstruction; Interdisciplinarity; Metaphor.
\end{abstract}

O discurso filosófico e, da mesma forma, o literário operam na oscilação e no embate, no agon de dois ou mais polos: agonia, fricção, rasura. Esse contato é o agono grego, elo linguístico proliferante que nos leva às assembleias, praças públicas e arenas, à agonística grega, em suma, que é tanto desportiva quanto retórica, vai da extensão dos músculos do corpo à distensão dos músculos da voz. Trata-se, simultaneamente, de espaço e ocorrência: nomeamos o lugar onde a dança, a luta e o ritual tomarão corpo e preenchemos esse vazio com o acontecimento, o combate. Mais além, a agonografia, o agonografar: a sistematização sobre o ato, o esboço que coordena os movimentos do guerreiro, do dançarino e do sacerdote, as marcações para a entrada em cena dos atores, as diretrizes para a produção dos filósofos.

* Kelvin Falcão Klein, Doutorando em Teoria Literária. Universidade Federal de Santa Catarina - UFSC. kelvin.klein@gmail.com 
Esse teatro de polos está presente desde a capa até o conteúdo: está no ser e no nada de Sartre, na diferença e repetição de Deleuze, ser e tempo em Heidegger, vontade e representação em Schopenhauer, verdade e método em Gadamer, voz e silêncio em Blanchot, e além. Planos que se encontram e se mesclam, gerando fantasmas e potências de pensamento quando postos em contato,pois é importante lembrar que, no deslizar do sentido e da leitura, o gono é também a fecundação que advém da fricção da luta, engendra, traz à luz o rebento, descendência, epígonos, prógonos (HOUAISS, 2001, p. 117 e 1466).

Giorgio Agamben mostra como, tanto em Platão (no diálogo Teeteto) quanto em Aristóteles (no De anima), podemos também encontrar uma preocupação com a potência do contato, em especial dentro de uma irredutível cumplicidade entre forma e conteúdo, dentro e fora, uma fuga do binarismo que ocupará lugar central em nossa argumentação. Agamben retoma os dois gregos em suas ideias sobre o ícone, a imagem e o fantasma, impressões que são realizadas em certa "cera impressionável" da alma. A ideia de impressão, efígie e ícone é anunciada aqui, neste início, porque sobreviverá na argumentação de Jacques Derrida, que, utilizando certa passagem de Anatole France, tomará para si a metáfora de uma moeda que passa pela usura, tendo sua face apagada. Essa moeda é a palavra no discurso filosófico metafísico: seu percurso arbitrário (o ser que aí permanece, no ato da impressão) é apagado, dando a ideia de uma naturalidade fabricada.

Aristóteles e Platão falam da cera que compõe o aparelho mnemônico (e a memória é ponto central da sobrevivência do resíduo) de cada um: parede sensível, mais maleável em uns que em outros, guardando impressões, improntas, fantasmas, enfim, marcas que não mantém relação com a materialidade daquilo que, de certa forma, representam. O conhecimento, o processo de intelecção, passa pelo reconhecimento desses fantasmas. A usura da cera é como a usura da moeda do discurso metafísico: apaga o processo de fixação do conhecimento (a violência e a agonia do saber) (AGAMBEN, 2007, p. 131-55).

Assim na literatura como na filosofia, e em tudo que é linguagem: confronto, ritual, encanação e reestreias. O Ulisses de Homero e o Ulisses de Joyce; o Joyce de Flann O'Brien (The Dalkey archive), de Tom Stoppard (Travesties), de Houaiss, Bernardina, Salas Subirat, José María Valverde e Valery Larbaud; o Robinson Crusoé de Daniel Defoe, J.M. Coetzee (Foe) e Michel Tournier (Vendredi ou la vie sauvage); a cosmogonia indígena brasileira em Hans Staden, Gandavo, Mário de Andrade (Macunaíma) e Alberto Mussa (Meu destino é ser onça). O ser se encontra na permutação, consigo e com os outros. 
Gilles Deleuze e Félix Guattari, em O que é a filosofia?, já mencionavam o agon que se dá entre os "amigos", os filósofos, amigos do saber, livre-pensadores: "a rivalidade dos homens livros, um atletismo generalizado: o agôn" (DELEUZE; GUATTARI, 1992, p. 12). E, mais adiante, "se a filosofia tem uma origem grega, como é certo dizê-lo, é porque a cidade, ao contrário dos impérios ou dos Estados, inventa o agôn como regra de uma sociedade de 'amigos"” (DELEUZE; GUATTARI, 1992, p. 17)

A cena se desdobra e agora os amigos em questão pronunciam discursos de campos distintos, heterotopias atravessadas e alimentadas mutuamente: literatura e filosofia. Comungam imagens, e nisso é possível observar regras e combinações de correlações, analogias e diferenças que dão relevo à proximidade, sobretudo na glosa e emulação do discurso de um campo a outro.

Estudos de nosso tempo o mostram: a literatura menor encontrada por Deleuze e Guattari em Kafka (Kafka: Por uma literatura menor) é mais do que identificação de temas e recorrências na obra de um autor determinado. Passa por isso para desembocar em um conceito que desestabiliza hierarquias, reivindica o fragmento, a incompletude e a indecidibilidade, sem concessões para a sacralização da verdade última ou da representação pura, na esteira do Baudelaire lido por Giorgio Agamben (Estâncias), Rousseau lido por Jacques Derrida (Gramatologia) e Raymond Roussel lido por Michel Foucault (Raymond Roussel).

Este último autor, sempre atento a certa lógica da apropriação continuamente operativa no discurso dos saberes, faz um diagnóstico preciso desse movimento. A passagem selecionada é o trecho de uma entrevista na qual Foucault comenta a obra de André Breton:

Toda a rede que percorre as obras de Breton, Bataille, Leiris e Blanchot, que percorre os domínios da etnologia, da história da arte, da história das religiões, da linguística, da psicanálise, apaga infalivelmente as velhas rubricas nas quais nossa própria cultura se classificava e revela aos nossos olhos parentescos, vizinhanças, relações imprevistas. (FOUCAULT, 2006, p. 246)

Outro momento de contato que podemos resgatar é a leitura que Benedito Nunes faz de Clarice Lispector na década de 1960. Sua aproximação do texto é tributária de certa leitura heideggeriana muito específica, uma 
hermenêutica do objeto sempre distante: é sempre o objeto, a barata, o ovo, e não o contato, a faísca do agon, a marca e o vestígio. Parte-se disso para se pensar, agora, a relação com, GH com a barata, com-temporâneos, suspensão da estratificação do sentido e atenção voltada para a simultaneidade da temporalidade envolvida na ocorrência de cada elemento (NUNES, 1989).

Iniciamos, portanto, com a ideia de conflito comungada por dois discursos distintos, o filósofico e o literário. Disso decorre um complexo jogo de velamento e desvelamento de procedimentos no nível da linguagem: omissões, atribuições, filiações, ênfases, recortes, montagens e figuras de retórica. A escritura apresenta suas intenções e, ao esboçar o movimento, deixa um flanco aberto, permitindo que outra voz fale dessa mesma escritura, em registro velado. É a isso que se refere Jacques Derrida em Margens da filosofia quando menciona

[...] a figura sensível que se acolhe e que se usa, até passar despercebida, em cada conceito filosófico. As noções abstratas escondem sempre uma figura sensível. E a história da língua metafísica confundir-se-ia com o apagamento da sua eficácia e a usura da sua efígie. A palavra não é pronunciada, mas pode-se decifrar a dupla dimensão da usura: o apagamento por fricção, por esgotamento, por esterilização, é certo, mas também o produto suplementar de um capital, a troca que, longe de perder a entrada, faria frutificar a riqueza primitiva, acrescentaria a paga sob a forma de lucros, de acréscimo de interesse, de mais-valia linguística, permanecendo as duas histórias do sentido indissociáveis. (DERRIDA, 1991, p. 250)

Derrida aponta para a indissociação das histórias que se acumulam para formar um sentido: a leitura sempre faz, conscientemente ou não, um percurso de pressupostos, uma sucessão de clivagens que se anunciam no texto, definidas ou mantidas segundo a cartografia que se realiza. A ênfase está nessa realização, nesse acontecimento da seleção e da leitura, espaço do ser em exercício de permutação. Acontecimento como entendido em A arqueologia do saber, de Foucault: irrupção de singularidade produtiva que ressoa, mas que não se remete, já que circunscrita ao seu momento de produção (FOUCAULT, 1972).

O horizonte do ser no saber e do saber no ser é, portanto, configurado como um processo tradutório, de contínuas idas e vindas de um campo ao outro. Reforço sobre a ideia da continuidade, atrelada a uma ideia que se anuncia, 
Palimpsetos e sobrevivênscias: o ser e o sentido na filosofia e na literatura

desde já, sob o signo da incompletude produtiva. O trânsito entre literatura e filosofia é a proposição de algo, um problema e também, simultaneamente, o abandono desse esforço, como na noção benjaminiana de tradução como Aufgabe: tarefa e desistência, persistência e descontinuidade.

Ao estabelecer uma leitura desconstrutiva de um texto de Benjamin ("Zur Kritik der Gewalt", por uma crítica da violência), Derrida aponta, em nota, como essa operação de contato com um texto oscila na impossibilidade, dela retirando sua vitalidade: "A desconstrução jamais se apresentou como algo possível. [...] ela nada perde ao confessar-se impossível" (DERRIDA, 2007, p. 73 ) - ao contrário, uma vez que Derrida deixa claro que a mobilidade crítica prescinde dos movimentos regrados e acessíveis, o desejo da desconstrução "é certa experiência do impossível: isto é [...] do outro, a experiência do outro como invenção do impossível" (DERRIDA, 2007, p. 73).

Derrida mostra que encontrar o ser na emergência do conceito faz parte da leitura desconstrutiva: a evidência do arbítrio do pensador/filósofo/escritor. Benjamin escreve sobre a possibilidade de se nomear a violência usando a fórmula die waltende heissen. Atentando para a nomeação (waltende), Derrida enxerga "o selo discreto e o prenome de sua assinatura", evidência do ser no deslizar da letra (Walter, waltende). (DERRIDA, 2007, p. 72).

O ser, na literatura e na filosofia, opera com o sentido no acontecimento da seleção. Derrida, ao comentar a condição de filólogos de Nietzsche e Renan, afirma que recordavam "a origem metafórica dos conceitos e nomeadamente daquele que parece sustentar o sentido próprio, o ser" (DERRIDA, 1991, p. 254). O ser não só está aí posto como produtor de metáfora (articulador de linguagem) mas também em alteridade e diferença, posto no limiar que "parece sustentar o sentido próprio", o sentido das metáforas, sem dúvida, e principalmente o sentido de metaforizar: deslocar, renomear, transpor, encobrir, contaminar, engendrar (o léxico de nossa agonística).

O indivíduo desconfia. Suspeita dos limites e dos cercados, criando para si explicações: pregas que se soltam, dobras que se desdobram em outras dobras. O que vem desse desconforto é sempre produzido, nunca está lá, "como corpos celestes", diz Deleuze, que continua: "Não há céu para os conceitos. Eles devem ser inventados, fabricados ou antes criados, e não seriam nada sem a assinatura daqueles que os criam" (DELEUZE, 1992, p. 13), e arremata, à frente: "a questão da filosofia é o ponto singular onde o conceito e a criação se remetem um ao outro" (DELEUZE, 1992, p. 13 e 20)-o agôn das formas de dizer do ser. 
As margens da filosofia, referidas por Derrida especialmente no texto "A mitologia branca", estão contidas nas metáforas que fabricam os enunciados filosóficos e apresentam as figuras que dão feições específicas ao pensamento. As metáforas cobrem todo o dizer filosófico, instantâneos do encontro do conceito com criação, e, segundo Derrida, configuram duplo registro: expandem vertiginosamente a trama da argumentação, encobrindo sua arbitrariedade mediante um jogo linguístico de naturalização. Escreve Derrida:

[...] o sentido visado através destas figuras é uma essência rigorosamente independente do que a transporta, o que é já uma tese filosófica, poder-se-ia mesmo dizer a única tese da filosofia, aquela que constitui o conceito de metáfora, a oposição do próprio e do não próprio, da essência e do acidente, da intuição e do discurso, do pensamento e da linguagem, do inteligível e do sensível, etc. (DERRIDA, 1991, p. 270)

O indivíduo que desconfia também procura apagar certos rastros, por costume, hábito, reflexo condicionado. Disso decorre uma busca pela essência estanque que é improdutiva, baseada em oposições binárias que congelam o sistema. O sentido que se encontra no fundo é uma essência estranha, o fundo da metáfora diz outra coisa, está alhures e é não próprio.

Como prolongamento dessas questões, podemos observar, rapidamente, uma passagem recente da literatura brasileira, que realiza (mais do que exemplifica) esse caráter errático e múltiplo da metáfora no discurso, assinatura (como vimos e veremos) contínua do ser ("A metáfora seria o próprio homem. E mais propriamente de cada homem, consoante a medida do gênio - da natureza - que nele domina." - DERRIDA, 1991, p. 287). A passagem a ser considerada é "Um conto abstrato", de Sérgio Sant'Anna, escritor carioca nascido em 1941, autor, entre outros livros, de $O$ concerto de João Gilberto no Rio de Janeiro, $O$ monstro, Um crime delicado e $O$ vôo da madrugada, de 2003, de onde extraio os seguintes trechos:

Um conto de palavras que valessem mais por sua modulação que por seu significado. Um conto abstrato e concreto como uma composição tocada por um grupo instrumental; [...] espiral azul num campo de narcisos defronte a uma torre a descortinar um lago assombrado [...] um conto em que os vocábulos são como notas indeterminadas numa pauta [...]. Um conto de semântica distorcida, de sons insuspeitados 
como o de cordas soadas pelo vento feito música do Uakti ou de Smetak, ou de instrumentos balineses cujos nomes são eles mesmos música: kazar, hemang, jogagan, kempur, réong, gangsa. (SANT'ANNA, 2003, p. 42-43)

O objeto de Sant'Anna é o próprio conto, que observa a si próprio ao longo de sua realização. O traço desliza observando o que deixou para trás, questionando o espaço que passa a ocupar no texto. Vai além de um hibridismo puro e simples, da reflexão e da experimentação filosófica que toma as feições da literatura. O conto é composto pela negação contínua de todos os lugares que sua escrita ocupa, ou seja, um sistema metaforizante que expõe suas substituições, deixando-as para trás em uma economia do dispêndio, até a aporia final.

É nesse percurso que nos aproximamos também das reflexões de Jacques Rancière sobre a escrita, e mais: a percepção de uma escrita literária que agrega vestígios, uma literatura do com, política do contato, em Rancière - "Diremos que existe um fenômeno de literaridade em todo lugar em que a escrita faz mais do que a materialidade de seu traçado; onde ela encena um saber ou significa sua falta; onde ela metaforiza seu sentido ou sua função." (RANCIÈRE, 1995, p. 98)

Vamos da materialidade do traçado para a problematização do sentido daquilo que se escreve e, principalmente, daquilo que se poderia escrever, pôr em evidência, mas que permanece no arquivo, em potência. $\mathrm{O}$ recorte $\mathrm{e}$ o deslocamento são os vetores que localizam essas possibilidades. O conto de Sant'Anna é, a partir disso, nada mais do que aquilo que se espera como o antes da escrita: esboços e tentativas, laboratório. Sant'Anna, portanto, abandona o bebê e cria a placenta, apresentando como obra aquilo que a convenção nomeia de rascunho e resíduo - ressignificando, dessa forma, a própria crítica que suscita.

Derrida nos apresenta o lado oposto, uma história que põe em evidência o fechamento do laboratório e do rastro. Estamos ainda em "A mitologia branca", no momento em que o autor retoma uma obra de Anatole France, Jardim de Epicuro, na qual ocorre um diálogo filosófico entre Poliphilo e Aristo, e de onde vem, justamente, a expressão mitologia branca.

Poliphilo tem um sonho no qual vê filósofos metafísicos operando palavras como um amolador operaria moedas: limando-as até ficarem lisas. Re- 
tirando o valor visível das moedas, as efígies e inscrições, os filósofos inserem esses objetos em uma instância sem tempo ou espaço, de valor infinito, ou seja, palavras correntes, com suas bagagens de usos e conotações, são ex-faceladas (para manter o jogo que realiza Derrida com a palavra effacer, ef-facemente, "apagar a face", limar o palimpsesto do sentido, que os tradutores mantêm como apagamento) e transformadas em conceito. Abandonam forçosamente o físico para entrar no metafísico.

Disso decorre um equívoco duplo, que se inicia de maneira paradoxal e se desenvolve de forma simultânea: a primeira face do equívoco é manter em circulação a moeda metafísica que passou pela usura (apagamento e multiplicação, lucros); a outra face é "a possibilidade de restaurar ou reativar [...] a 'figura original' da peça usada apagada, polida pela circulação do conceito filosófico" (DERRIDA, 1991, p. 251). Procedimentos tautológicos, em que a resposta está dada de antemão, como no reconhecimento das séries numéricas que ocorre na lavagem de dinheiro, já que nesse contexto "a filosofia seria este processo de metaforização que se conduz a si mesmo", em que "o filósofo apenas encontrará aí o que lá pôs ou, pelo menos, o que enquanto filósofo acreditou ter aí posto" (DERRIDA, 1991, p. 269).

Trabalhar no palimpsesto que aí se revela é imprescindível, já que encontramos o ser conferindo sentido na simultaneidade das camadas. Não há, contudo, sobredeterminação da essência ou da origem nesse percurso, uma vez que encontramos um centro descentrado, disseminado em múltiplos começos. Há rigor (também imprescindível) no estabelecimento dos marcos desse percurso, mas há também mobilidade e com-temporarização: o segundo passo de um percurso pode ser o penúltimo de outro, ou ainda o início de um terceiro. Nisto voltamos a Deleuze: "aqueles que criticam sem criar, aqueles que se contentam em defender o que se esvaiu sem saber dar-lhe forças para retornar à vida, eles são a chaga da filosofia. São animados pelo ressentimento." (DELEUZE, 1992, p. 42).

Emerge a questão da sobrevivência e do dispêndio: saber ver o que há de potência naquilo que aparentemente se esvaiu, ou seja, atentar para o retorno da usura, o lucro e os juros, figuras da latência. Nesse ponto, Derrida convoca Saussure, especificamente uma passagem de seu Curso na qual esquematiza o lado econômico da linguagem, utilizando, como é óbvio, elementos monetários, em uma analogia entre a economia e a linguística.

Trata-se de incorporar à língua a noção de valor, que sempre remete a um sistema de equivalência entre coisas de ordens distintas: o trabalho está 
para o significante assim como o salário está para o significado. Derrida cita Saussure no momento em que este diz que, para saber o valor de uma moeda de cinco francos parte-se primeiro para o dissemelhante que se troca (moedas por pão), e depois para o semelhante que se compara (a moeda de cinco francos diante de uma nota de dez dólares). Da mesma forma para a língua: uma palavra trocada por uma ideia (dissemelhante), e uma palavra em confronto com outra palavra (semelhantes). Os dois níveis se misturam: confrontamos palavras umas com as outras para decidir qual delas casa melhor com uma ideia ou conceito, arrastamos o conceito pelas palavras em busca de explicação, luzes sobre os interstícios das pregas do pensamento. Exaurir esse percurso do hibridismo do discurso é permanente "condição de impossibilidade" (DERRIDA, 1991, p. 257-59).

A moeda de Derrida - que ele trocou com Anatole France, com Saussure, com Heidegger e Nietzsche (Contato com dissemelhante ou semelhante? Que troca opera em cada caso? Qual a fórmula da mistura? Até que ponto encontrou o que já havia posto ali? - questões que ficam em potência) -, a moeda-palimpsesto, encerra em si a manufatura do fundo do sentido e os vestígios de muitas digitais: marcas do sujeito que acessa o arquivo e articula sobrevivências. Tal como faz Jean Starobinski, em troca (contato) com o mesmo Saussure: As palavras sob as palavras, imersão nos arquivos de Saussure, nas bordas obliteradas de suas reflexões, incompletudes que são utilizadas por Starobinski para sentir a vibração do ruído, do silêncio, da obra em potência de Saussure, certa encenação da falta, vista em Rancière e Sant'Anna. Gesto de escuta que remete ao fantasma e gesto de leitura que remete ao resíduo (STAROBINSKI, 1974).

Essa moeda segue sua viagem como palimpsesto dos discursos. E parece já evidente que solicita um procedimento mais de análise que de descrição: a moeda prenhe de ornamentos é uma imagem que funda para si uma iconologia, em detrimento de uma iconografia. Abandona o elenco ordenado de características estanques para fluir no confronto de heterogeneidades e heterotopias. Buscar resíduos no arquivo é trocar a grafia pela logia, como apontou Erwin Panofski, na esteira de Aby Warburg, uma vez que as imagens estão aí como linguagem, íntimas dessas figuras da metaforização que mesclam literatura e filosofia (CALABRESE, 1987, p. 27-30).

Omar Calabrese comenta Ernst Gombrich em direção a essa guinada que a imagem da moeda nos oferta: "A chamada representação pictórica seria 
substancialmente sempre determinada por convenções, normas que organizam a percepção, tornando-a pertinente e depois transpondo-a tecnicamente em uma linguagem." (CALABRESE, 1987, p. 58). Conceito, ideia, metáfora, literatura, ficção: todo um aparato convencionado que partilha um esforço de encobrimento, de velamento dos procedimentos daquilo que realiza.

No fim desse percurso, vemos a confluência de diferentes registros, que parecem convergir para uma trama luminosa na qual todas as junções e nós são, simultaneamente, inícios, meios e fins: as figuras dos saberes olham-se em espelhos múltiplos (e lembramos Agamben: "só uma 'disciplina da interdisciplinaridade' é adequada para a interpretação dos fenômenos humanos" - AGAMBEN, 2007, p. 153). Pensar com categorias estanques torna-se, contemporaneamente, mais do que tempo jogado fora: configura-se como um desserviço, como um engessamento do fluxo do saber humano.

Georges Didi-Huberman, em livro recente sobre o sistema de estudo comparado das culturas de Aby Warburg, faz uma analogia semelhante àquela que Derrida realiza com Saussure, da linguística com a economia, em que podemos vislumbrar essa confluência mencionada em pleno funcionamento. Didi-Huberman vê em Warburg uma analogia entre imagem e linguagem: atrás de certa "força formadora do estilo", atrelada a uma "amplificação do movimento", Warburg nota que certos adjetivos e verbos, ao mudarem de radical em um processo de intensificação das ideias por analogia, longe de perderem contato com o primeiro termo, intensificam o mesmo, por conta das heterogeneidades que implementam em sua cadeia significativa.

Assim na imagem como na linguagem: Warburg, então, observa que essa intensificação por heterogeneidade (ou étrangeté, nas palavras de Didi-Huberman: "c'est l'étrangeté qui prend ici le pouvoir d'intensifier un geste présent en le vouant au temps fantomal des survivances" - DIDI-HUBERMAN, 2002, p. 252) está nas feições de uma Ménade grega que aparecem na representação de uma Salomé bíblica e na representação que faz o artista Ghirlandaio de um criado no Renascimento, cujos gestos reproduzem certa figura em um arco do triunfo romano.

Todas essas instâncias remetem ao universo do simbólico, patrimônio do pensamento dividido entre muitas mãos (moedas tilintando no interior de incontáveis bolsos). Estética e ética estão em contato nessa passagem, nessa atualização que acontece quando uma imagem troca de mãos. O ser que agrega sentido é um gesto de desleitura de qualquer origem: retorna sempre em suas ressignificações. 
Palimpsetos e sobrevivênscias: o ser e o sentido na filosofia e na literatura

\section{Referências}

AGAMBEN, Giorgio. Estâncias: a palavra e o fantasma na cultura ocidental. Belo Horizonte: Editora UFMG, 2007.

CALABRESE, Omar. A linguagem da arte. Rio de Janeiro: Globo, 1987.

DELEUZE, Gilles; GUATTARI, Félix. O que é a filosofia? Rio de Janeiro: Editora 34, 1992.

Kafka: por uma literatura menor. Rio de Janeiro: Imago, 1977.

DERRIDA, Jacques. Força de lei: o fundamento místico da autoridade. São Paulo: Martins Fontes, 2007.

. Margens da filosofia. Campinas: Papirus, 1991.

DIDI-HUBERMAN, Georges. L'image survivante: histoire de l'art et temps des fantômes selon Aby Warburg. Paris: Minuit, 2002.

FOUCAULT, Michel. Estética: literatura e pintura, música e cinema. Rio de Janeiro: Forense universitária, 2006.

A arqueologia do saber. Petrópolis: Vozes, 1972.

HOUAISS, Antonio. Dicionário Houaiss da língua portuguesa. Rio de Janeiro: Objetiva, 2001.

NUNES, Benedito. O drama da linguagem: Uma leitura de Clarice Lispector. São Paulo: Ática, 1989.

RANCIÈRE, Jacques. Políticas da escrita. Rio de Janeiro: Editora 34, 1995.

SANT'ANNA, Sérgio. O vôo da madrugada. São Paulo: Companhia das Letras, 2003.

STAROBINSKI, Jean. As palavras sob as palavras. São Paulo: Perspectiva, 1974.

Recebido para publicação em 17 de julho de 2009.

Aceito para publicação em 08 de março de 2010. 